\title{
Menstrual Abnormalities and Gynaecological Problems in Women on Anticoagulant and Antiplatelet Therapy: Management Options
}

\author{
Pratibha Devabhaktuni' ${ }^{1}$, Precella Thomas ${ }^{1}$, Anuj Kapadia ${ }^{2}$, Sridevi $^{2}$, Somaraju Bhupatiraju² \\ ${ }^{1}$ Department of Obstetrics and Gynaecology, CARE Institute of Medical Sciences, Hyderabad, India \\ ${ }^{2}$ Department of Cardiology, CARE Institute of Medical Sciences, Hyderabad, India \\ Email:dpdnk@yahoo.com
}

How to cite this paper: Devabhaktuni, P., Thomas, P., Kapadia, A., Sridevi and Bhupatiraju, S. (2017) Menstrual Abnormalities and Gynaecological Problems in Women on Anticoagulant and Antiplatelet Therapy: Management Options. Open Journal of Obstetrics and Gynecology, 7, 581-599. https://doi.org/10.4236/ojog.2017.75061

Received: April 14, 2017

Accepted: May 23, 2017

Published: May 26, 2017

Copyright $\odot 2017$ by authors and Scientific Research Publishing Inc. This work is licensed under the Creative Commons Attribution International License (CC BY 4.0).

http://creativecommons.org/licenses/by/4.0/

(c) (i) Open Access

\begin{abstract}
Introduction: The aim of this study was: 1) To study the pattern of menstrual abnormality and severity in women on anticoagulant and antiplatelet drugs. 2) To analyze the correlation of prothrombin time (PT), International Normalised ratio (INR) and the bleeding severity. 3) To discuss the various management options in unexpected emergencies and menstrual complications in this subset of women on anticoagulants. Material \& Methods: It is a prospective study, over a period of 18 months from July 2011 to december 2012. We had 44 women on antithrombotic therapy. 32 women were on anticoagulants and 12 were on antiplatelet agents. The severity of bleeding pattern was assessed with pictoral bleeding assessment chart (PBAC). 1) Out of 44 women studied, 32 women were on anticoagulants and 12 were on antiplatelet agents. $26(81.25 \%)$ were on acenocoumarol, $5(15.62 \%)$ on warfarin, 1 (3.12\%) on heparin, among the 12 antiplatelet users, $8(66.66 \%)$ were on aspirin and 4 (33.33\%) on clopidogrel. 2) The indication for anticoagulants was mitral valve replacement (MVR) in 9, double valve replacement (DVR) in 6, aortic valve replacement (AVR) in 3, severe pulmonary artery hypertension (PAH) in 2, severe mitral stenosis (MS) with atrial thrombus in 2, deep vein thrombosis (DVT) in 5, severe mitral regurgitation (MR) in one, the other indications were subdural hematoma, thromboendarterectomy, chronic kidney disease (CKD) stage $\mathrm{V}$, coarction of aorta, one each. The indication for antiplatelet therapy was percutaneous transluminal coronary angioplasty (PTCA) in 3, Wolf Parkinson White (WPW) syndrome + atrial fibrillation (AF), acute myocardial infarction (AMI), coronary artery bypass graft (CABG), mid basilar artery aneurysm, renal allograft recipient, dialated cardiomyopathy, aortic aneurysm repair, hypertension and unstable angina one each. Results: In women on anticoagulants (32), the main complaint was menorrhagia/heavy menstrual bleeding (HMB) in 20 , polymenorrhoea with menorrhagia in 4 ,
\end{abstract}


continuous per vaginal (PV) bleeding in 6. One lady had postmenopausal bleeding. Among the 12 antiplatelet users the main complaint was menorrhagia in 8 , polymenorrhoea with menorrhagia in 2, postmenopausal bleeding in one. While on antithrombotic therapy apart from heavy menstrual bleeding, two women had intraperitoneal bleeding, two had post menopausal bleeding, two had secondary postpartum bleeding (PPH). CVA due to embolic stroke occurred in three, one during the study period. Subchoroidal haemorrhage causing choroidal detachment was noted in one. Conclusions: In patients with prolonged INR, excessive uterine bleeding can be an alerting initial manifestation. Antithrombotic therapy can cause HMB or exaggerate the symptom of HMB due to an underlying gynaec pathology. Mefanamic acid and norethisterone were used to arrest heavy menstrual bleeding. Antithrombotic therapy in women needs special consideration with alterations in menstrual pattern and contraception. Pregnancy and postpartum period present special challenges.

\section{Keywords}

Anti thrombotic Therapy in Women, Anticoagulants, HMB, $\mathrm{PMB}, \mathrm{PPH}$

\section{Introduction}

Chronic antithrombotic therapy involves the use of anticoagulants, antiplatelets given either as monotherapy or in combination for the prevention of thrombotic complications. The most feared and sometimes fatal complication with this therapy is bleeding. Anticoagulant therapy is mandatory in various diseases, such as in the postoperative period following cardiac valve replacement. The estimated incidence of venous thromboembolism (VTE) in women of reproductive age is 1 - 10 per 10,000 women per year. Deep vein thrombosis and pulmonary embolism are nearly always treated with oral anticoagulation (OA). Treatment can be either lifelong or limited for a period ranging from 6 weeks to a year, depending on the number and severity of thromboembolic events.

With the use of warfarin, the International Normalized Ratio (INR) that has been established to indicate adequately balanced therapy is between 2.0 and 3.0. The well-established benefits of anticoagulant therapy are significantly hampered by the possibility of major and sometimes fatal bleeding complications.

Bleeding can be classified as: a) major bleeding (that may include bleeds causing death or being life threatening, those requiring operation or medical intervention to stop bleeding, or causing permanent symptomatic organ damage or permanent changes in antithrombotic therapy). b) clinically relevant non major bleeds ( requiring cessation of antithrombotic therapy, and or change in therapeutic management), or c) minor (with minimal impact on clinical status of patients) [1]. The risk of bleeding on VKAs in prospective studies has been reported to be: a) $0.1 \%-1.0 \%$ patient-years of treatment for fatal episodes, b) $0.5 \%-6.5 \%$ for major episodes and c) $6.2 \%-21.8 \%$ for minor bleeding. A sig- 
nificant clinical impact of bleeding in patients anticoagulated for venous thromboembolism (VTE) has been demonstrated in a recent meta-analysis that reported a case fatality rate of major bleeding of $13.4 \%$ in all patients, with a rate of intracranial haemorrhage (ICH) of $1.15 \%$ per year [2].

Unfortunately, the need is not uncommon for antiplatelet (ASA + clopidogrel) and an anticoagulant combination in patients with heart valve prosthesis, $\mathrm{AF}$, and acute coronary events or coronary stenting. In these pathological conditions, the theoretical advantage of thrombotic prevention should be considered against the risk of bleeding [3] [4].

Hansen et al. [5] found in patients with AF that combinations of warfarin, aspirin, or clopidogrel were associated with an increased risk of fatal and nonfatal bleeding.

Unique issues for women of reproductive age: 1) Menstrual problems can be exacerbated by anticoagulation [6]. 2) Warfarin is a known teratogen [7]. Data on the safety of use of newer anticoagulants including dabigatran or rivaroxaban during pregnancy is not yet available. 3) Hemorrhagic ovarian cysts, which can be life-threatening, are estimated to affect $1 \%$ of women receiving anticoagulation medications [8]. 4) Pregnancy and the postpartum period increase women's risk of thrombosis and therefore require careful planning and awareness of the potential signs/symptoms of thrombotic events. 5) Warfarin is considered safe to use while breastfeeding [9]. 6) The efficacy and safety of the use of tranexamic acid in patients at higher risk for thromboembolism (such as those requiring anticoagulation) have not been established, but in general, these patients should not receive tranexamic acid. 7) Emergency contraceptive pills can be safely used following a contraceptive emergency by women who require anticoagulation [10].

Prevention of Hemorrhagic Ovarian Cysts: 1) Hormonal treatments may be used to suppress ovulation and formation of ovarian cysts. 2) Progestin-only methods which consistently suppress ovulation include the etonogestrel implant and DMPA. 3) The levonorgestrel IUD and progestin-only pills suppress ovulation for some, but not all, women, [11] [12]. 4) Hemorrhagic ovarian cysts occur more frequently when INR $>4$.

Why patients bleed? "The Golden Rule" in antithrombotic therapy: An abundance of literature supports what we have called "The Golden Rule" in antithrombotic therapy [13]. Bleeding charts such as the HAS-BLED have been proposed to estimate the bleeding risk, including intracranial bleeding in AF patients on anticoagulant therapy with warfarin [14] [15] [16] [17] [18]. The HASBLED score includes hypertension, renal conditions, and/or liver disease, history of stroke, bleeding, the INR lability, age over 65 years, and alcohol or drug intake [15]. Despite its popularity, the clinical significance of 7 scoring systems for risk of bleeding events in patients on anticoagulant therapy was poor and no better than the subjective evaluation of a physician [19].

Aim: CARE hospital being a Cardiac, CT surgery and Vascular surgery centre, it is not uncommon to see women on anticoagulants and antiplatelet drugs. It is our endeavour to emphasize the work up and management of menstrual prob- 
lems, challenges and complications in women on anticoagulant and antiplatelet drugs for various indications.

\section{Method}

Women on anticoagulant and antiplatelet agents with menstrual problems, excessive and unscheduled bleeding per vaginum, advice regarding contraception and subfertility when referred to the gynaecologist the following protocol in history taking and assessment was followed.

History. How long have periods been heavy, is there flooding or passage of clots, how long do periods last and how often do they occur, has there been any change, is there any intermenstrual bleeding or post-coital bleeding, is there pelvic pain or dyspareunia, what contraception is being used and are cervical smears up to date (according to local screening programmes).

Assessment. Undertake pelvic examination and cervical smear (according to local screening programmes), haematology and biochemistry, imaging, endometrial sampling, hysteroscopy.

Assessing heavy bleeding in a clinical setting has its limitations. Hallberg and associates [20] describe a technique to extract hemoglobin from sanitary napkins using sodium hydroxide. Hemoglobin is converted to hematin and can be measured spectrophotometrically. The constraints to this approach in a clinical setting are obvious. Of note women find it very difficult to assess accurately the amount of blood loss. Thus, in clinical practice only $40 \%$ of women complaining of menorrhagia have measured losses greater than $80 \mathrm{ml}$ [21]. The alkaline haematin method is considered to be the "gold standard" for measuring menstrual blood loss [20]. Here sanitary devices are soaked in 5\% sodium hydroxide to convert the blood to alkaline haematin whose optical density is then measured. Since it is not routinely available various pictorial scoring systems have been proposed but reliability is conflicting [21] [22] [23].

Pictorial bleeding assessment chart is a tool widely used in research settings to quantify menstrual blood loss. A pictorial chart score of 100 or more has been shown to have a specificity and sensitivity of $80 \%$ when used as a diagnostic test for HMB. F.Y. Huq et al. [6] showed that $60 \%$ of women using OA have HMB, with a longer duration of menstruation. They are also more likely to experience episodes of flooding and the passage of clots during menstruation as well as intermenstrual bleeding.

Other tools used to estimate menstrual blood loss include hemoglobin and hematocrit evaluation. Hemoglobin concentration $<12 \mathrm{~g} / \mathrm{dL}$ increases the chance of identifying women with menorrhagia. A normal level, however, does not exclude menorrhagia, as many women with clinically significant bleeding have normal values.

Another method involves estimating of the number and type of pads used by a woman during menses. Warner and colleagues [24] found positive correlations between objective menorrhagia with passing clots more than 1.1 inches in diameter and changing pads more frequently than every 3 hours. Attempts to 
Name:

Day start: $L+|+|+\mid$ Patient No: year month day

\begin{tabular}{|c|l|l|l|l|l|l|l|l|}
\hline Pads & 1 & 2 & 3 & 4 & 5 & 6 & 7 & 8 \\
\hline- & & & & & & & & \\
\hline & & & & & & & & \\
\hline & & & & & & & & \\
\hline $\begin{array}{c}\text { Clots/ } \\
\text { Flooding }\end{array}$ & & & & & & & & \\
\hline
\end{tabular}

\begin{tabular}{|c|l|l|l|l|l|l|l|l|}
\hline Tampon & 1 & 2 & 3 & 4 & 5 & 6 & 7 & 8 \\
\hline$\square$ & & & & & & & & \\
\hline \\
\hline
\end{tabular}

Figure 1. The pictorial bleeding assessment chart.

standardize this type of evaluation have lead to development of the pictorial blood assessment chart (Figure 1).

Scores are assigned as follows: 1 point for each lightly stained tampon, 5 if moderately saturated, and 10 if completely soaked. Pads are similarly given ascending scores of 1,5 , and 20 , respectively. Small clots score 1 point, whereas large clots score 5 . Totals more than 100 points per menstrual cycle have been shown to indicate $>80-\mathrm{mL}$ objective blood loss [22] [25] [26]. Patients are counseled to evaluate the degree of saturation for each sanitary product used during menstruation. The total number of each type of sanitary product is then listed in the corresponding row during each day of menstruation.

Limitations of the study: The number of cases is small, the study period is only for 18 months, the influence of patient-level variables on the association between anticoagulant intensity and risk of events has not been analysed.

\section{Observations and Results}

\section{1) Age}

In this study out of the total 44 cases, 32 were on anticoagulants. The maximum cases were in the age group $21-30$ yrs (40.6\%). $28.12 \%$ were in the age group of $41-50,21.8 \%$ in $31-40$ yrs, $6.25 \%$ in $50-60$ yrs. One case was 16 yrs and presented with menorrhagia. In this study out of the total 44 cases, 12 cases were on antiplatelet drugs. The maximum cases were in the age group $41-50 \mathrm{yrs}$ (66.66\%). 8.3\% each in the age group of 21 - 30, 31 - 40 yrs, 50 - 60 yrs. One case was $78 \mathrm{yrs}$ and presented with post menopausal spotting per vaginum (PV). Figure 2. 

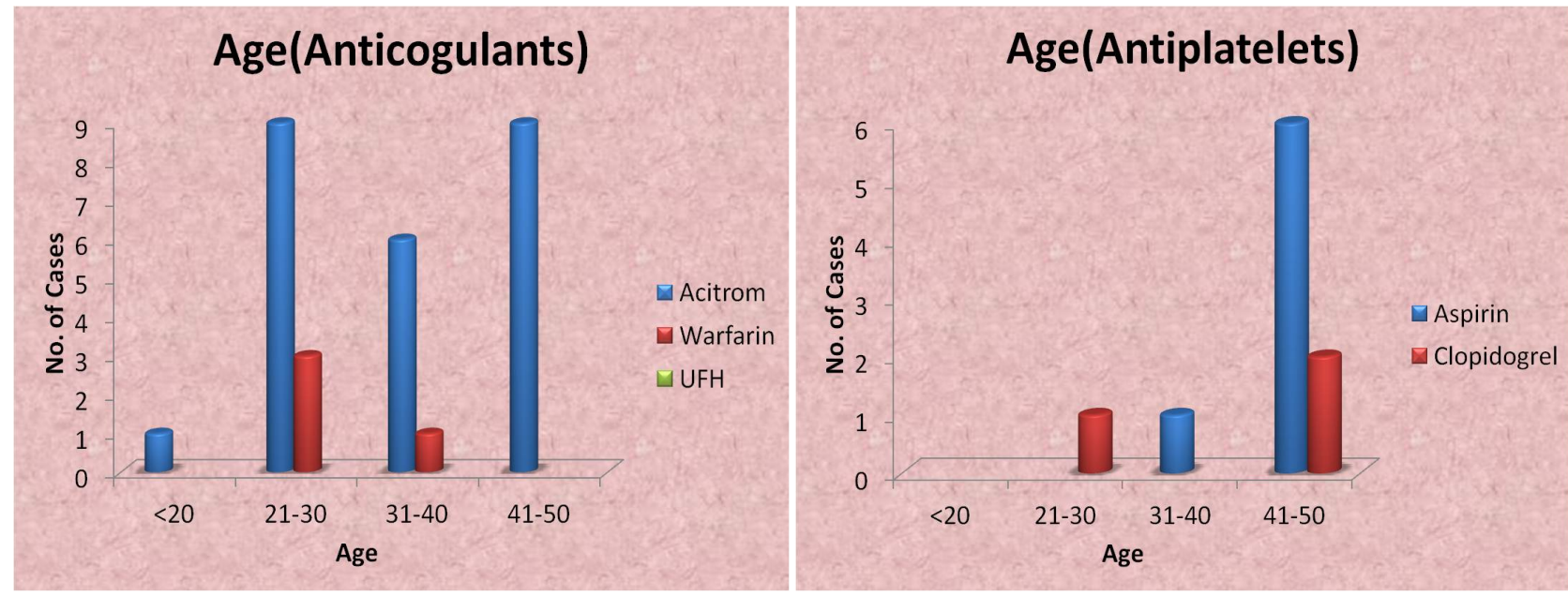

Figure 2. Anticoagulants \& Antiplatelets: number of cases in different age groups.

Table 1. Menstrual problems in users of anticoagulants and antiplatelet drugs.

\begin{tabular}{|c|c|c|c|c|c|}
\hline \multirow{2}{*}{ Menstrual Abnormality } & \multicolumn{3}{|c|}{ ANTICOAGULANTS } & \multirow{2}{*}{ Total } & \multirow{2}{*}{$\%(\mathrm{n}=32)$} \\
\hline & ACITROM & WARFARIN & UFH & & \\
\hline Menorrhagia & 18 & 2 & - & 20 & 62.5 \\
\hline Menorrhagia + Polymenorrhea & 4 & - & - & 4 & 12.5 \\
\hline Continuous PV Bleeding & 2 & 3 & 1 & 6 & 18.75 \\
\hline Post Menopausal Bleeding & 1 & - & - & 1 & 3.12 \\
\hline No Complaints & 1 & - & - & 1 & 3.12 \\
\hline Total & 26 & 5 & 1 & 32 & \\
\hline \multirow{2}{*}{ Menstrual Abnormality } & \multicolumn{3}{|c|}{ ANTIPLATELETS } & \multirow{2}{*}{ Total } & \multirow{2}{*}{$\%(\mathrm{n}=12)$} \\
\hline & ASPIRIN & \multicolumn{2}{|c|}{ CLOPIDOGREL } & & \\
\hline Menorrhagia & 6 & \multicolumn{2}{|c|}{2} & 8 & 66.66 \\
\hline Menorrhagia + Polymenorrhea & - & \multicolumn{2}{|c|}{2} & 2 & 16.3 \\
\hline Continuous PV Bleeding & - & \multicolumn{2}{|c|}{-} & - & - \\
\hline Post Menopausal Bleeding & 1 & \multicolumn{2}{|c|}{-} & 1 & 8.3 \\
\hline No Complaints & 1 & \multicolumn{2}{|c|}{-} & 1 & 8.3 \\
\hline Total & 8 & \multicolumn{2}{|c|}{4} & 12 & \\
\hline
\end{tabular}

\section{2) Menstrual abnormality}

The most common menstrual problem among the anticoagulant (AC) users was menorrhagia, /heavy menstrual bleeding (HMB) seen in $62.5 \%(20 / 32)$, polymenorrhea with menorrhagia was seen in $12.5 \%(4 / 32) .18 .75 \%$ (6/32) patients presented with continuous bleeding per vagina. One menopausal patient with postmenopausal bleeding accounting to $3.12 \%$. One case $(3.12 \%)$ had no menstrual complaints but presented with pain in abdomen. In this study, among the antiplatelet (AP) users the main complaint was menorrhagia seen in $66.66 \%$ (8/12), polymenorrhea with menorrhagia was seen in $16.3 \%(2 / 12)$. One menopausal patient with postmenopausal bleeding accounting to $8.3 \%$. One case (8.3\%) had no menstrual complaint Table 1. 


\section{3) Contraception}

Out of the 32 cases, 4 cases were in puerperal period and 2 were unmarried, all the 6 not requiring any contraceptive method. Eighteen out of $26(69.23 \%)$ had undergone tubectomy, $15.38 \%$ (4/26) were using barrier method. $15.38 \%(4 / 26)$ were not using any method. Eleven out of 12 AP users (91.6\%) had undergone tubectomy, $8.3 \%(1 / 12)$ one was not using any method.

\section{4) Co-morbid conditions}

In this study, among the anticoagulant users $6.25 \%(2 / 32)$ cases were noted having diabetes, $15.62 \%(5 / 32)$ were having pre existing hypertension. 9.37\% $(3 / 32)$ of the cases had co existing hypothyroidism and on adequate treatment. $15.62 \%$ cases had various other conditions.

In this study, $66.66 \%(8 / 12)$ of the antiplatelet users had hypertension, $25 \%$ (3/12) had diabetes. $41.66 \%(5 / 12)$ had hypothyroidism on adequate treatment. One case (1/12) had IgA nephropathy.

\section{5) Drugs}

Out of the total 44 cases, 32 were on anticoagulants and 12 on antiplatelet drugs. Majority of the cases, 26 were on acitrom and 5 on warfarin. Among the antiplatelet group, majority, 8 were on aspirin and 4 on clopidogrel (Table 2).

\section{6) Indication for anticoagulant and antiplatelet drugs}

Of the 32 cases on anticoagulants the indication in 9 (28.12\%) of them was mitral valve replacement (MVR), 6 (18.75\%) had double valve replacement (DVR) and 3(9.37\%) had aortic valve replacement (AVR). For 2(6.25\%)cases it was severe pulmonary artery hypertension (PAH), severe mitral stenosis (MS) with atrial thrombus. 5/32(15.62\%) cases it was due to DVT, the other indications were Subdural hematoma, thromboendarterectomy, chronic kidney disease (CKD) stage V, Coarction of aorta in 3.12\% (1/32) each.

Of the 12 cases on antiplatelets drugs, the indication was PTCA in 25\% (3/12).

Table 2. Anticoagulants and antiplatelet agents: Monotherapy and Combined therapy.

\begin{tabular}{|c|c|c|c|c|}
\hline Sl no & ANTICOAGULANT DRUGS & No. of cases & Total & $\%(n=32)$ \\
\hline 1 & WARFARIN & 5 & 5 & 15.62 \\
\hline \multirow[t]{3}{*}{2} & ACITROM & 22 & & \\
\hline & ACITROM + LMWH & 1 & 26 & 81.25 \\
\hline & ACITROM + ASPIRIN & 3 & & \\
\hline \multirow[t]{3}{*}{3} & UNFRACTIONATED HEPARIN & 1 & 1 & 3.12 \\
\hline & TOTAL & 32 & 32 & \\
\hline & ANTIPLATELET DRUGS & No. of cases & Total & $\%(\mathrm{n}=12)$ \\
\hline 1 & ASPIRIN & 8 & 8 & 66.66 \\
\hline \multirow[t]{2}{*}{2} & CLOPIDOGREL & 2 & & \\
\hline & & & 4 & 33.33 \\
\hline \multirow[t]{2}{*}{3} & CLOPIDOGREL + ASPIRIN & 2 & & \\
\hline & TOTAL & 12 & 12 & \\
\hline
\end{tabular}


Table 3. Indication for use of anticoagulants and antiplatelet agents.

\begin{tabular}{|c|c|c|c|c|c|}
\hline ANTICOAGULAN & & & & & \\
\hline INDICATION & ACITROM & WARFARIN & UFH & Total & $\%(\mathrm{n}=32)$ \\
\hline Severe PAH & 2 & - & - & 2 & 9.37 \\
\hline DVR & 5 & 1 & - & 6 & 18.75 \\
\hline MVR & 8 & 1 & - & 9 & 28.12 \\
\hline AVR & 3 & - & - & 3 & 9.37 \\
\hline Severe MS with atrial thrombus & 2 & - & - & 2 & 6.25 \\
\hline Severe MR + commissural tear & 1 & - & - & 1 & 3.12 \\
\hline DVT & 3 & 2 & - & 5 & 15.62 \\
\hline Subdural hematoma & - & 1 & - & 1 & 3.12 \\
\hline Thrombo end arterectomy & 1 & - & - & 1 & 3.12 \\
\hline CKD stage $\mathrm{V}$ & - & - & 1 & 1 & 3.12 \\
\hline Coarctation of aorta & 1 & - & - & 1 & 3.12 \\
\hline Total & 26 & 5 & 1 & 32 & \\
\hline ANTIPLATELET DRUGS & \multicolumn{3}{|c|}{ NO. OF CASES } & \multirow{2}{*}{ - Total } & \multirow{2}{*}{$\%(\mathrm{n}=12$} \\
\hline INDICATION & \multicolumn{3}{|c|}{ CLOPIDOGREL } & & \\
\hline PTCA & \multicolumn{3}{|c|}{1} & 3 & 25 \\
\hline $\mathrm{WPW}$ syndrome $+\mathrm{AF}$ & \multicolumn{3}{|c|}{-} & 1 & 8.3 \\
\hline AMI & \multicolumn{3}{|c|}{1} & 1 & 8.3 \\
\hline CABG & \multicolumn{3}{|c|}{-} & 1 & 8.3 \\
\hline Mid basilar artery aneurysm & \multicolumn{3}{|c|}{-} & 1 & 8.3 \\
\hline Renal allograft recepient & \multicolumn{3}{|c|}{-} & 1 & 8.3 \\
\hline Dilated cardiomyopathy & \multicolumn{3}{|c|}{-} & 1 & 8.3 \\
\hline Aortic aneurysm repair & \multicolumn{3}{|c|}{1} & 1 & 8.3 \\
\hline Hypertension & \multicolumn{3}{|c|}{-} & 1 & 8.3 \\
\hline Unstable angina & \multicolumn{3}{|c|}{1} & 1 & 8.3 \\
\hline Total & \multicolumn{3}{|c|}{4} & 12 & \\
\hline
\end{tabular}

The indications were Wolf Parkinson White (WPW syndrome) + atrial fibrillation (AF), acute myocardial infarction (AMI), CABG, Mid basilar artery aneurysm, renal allograft recipient, dialated cardiomyopathy, aortic aneurysm repair, hypertension, unstable angina in $8.3 \%$ (1/12) each (Table 3$)$.

\section{7) Complications}

Catastrophic life threatening complications were noted in 7 cases $(21.87 \%)$. CVA with embolic stroke accounted for $42.8 \%$ (3/7) of the complications with residual paralysis in 2 of the 3 cases. The thromboembolic episode had occurred before the patient was included in the study period. During the episode it was seen that INR was in the sub-therapeutic range.

One patient was noted to have Subchoroidal and vitreous haemorrhage with choroidal detachment. The event occurred before inclusion into the study pe- 


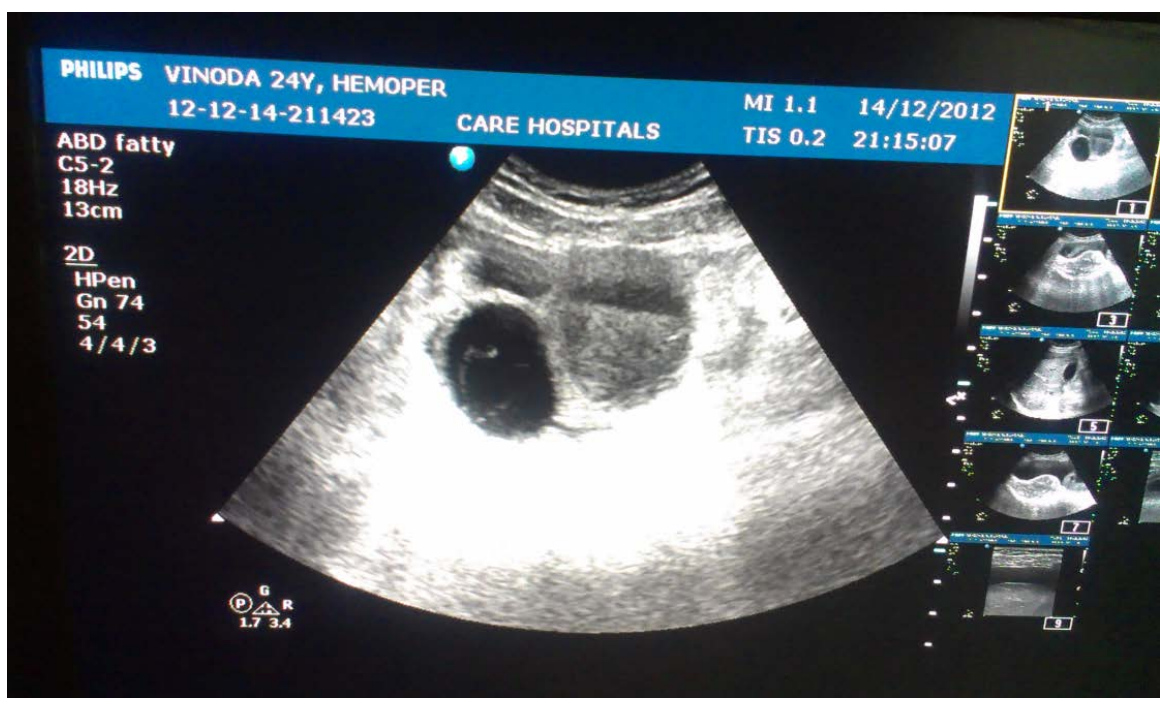

Figure 3. Intra-peritoneal bleeding due to rupture of a cyst in ovary.

riod. She was treated with laser pan photocoagulation.

Three of the 7 complications occurred during the study period. Two cases had major intraperitoneal bleeding. One was due to rupture of corpus luteal cyst of ovary, she was found to have severe anaemia. She was given 2 PRBC transfusions and anticoagulants were stopped for 3 days. IV antibiotic coverage was given.Evaluated with serial daily ultrasound for monitoring of regression of intraperitoneal haemorrhage (Figure 3). And other case was due to rupture of haemorrhagic cyst of ovary. Both cases were noted to have increased INR. There was no menstrual complaint in both the cases. Both were treated by conservative measures.

One case, during the seventh month of pregnancy developed left lower limb deep vein thrombosis. She was started on LMWH $60 \mathrm{mg}$ sc twice a day. IVC filter was placed. LMWH was stopped $12 \mathrm{hrs}$ prior to induction. She had vaginal delivery. After 3 days oral anticoagulation with warfarin was started. Patient presented to the hospital ten days after discharge with heavy bleeding per vaginum. She was treated as a case of secondary PPH. Warfarin dose was readjusted.

8) BMI

In this study, among the anticoagulant users, $71.8 \%(23 / 32)$ were noted to have BMI in the range of $19-25,21.28 \%(7 / 32)$ were in $26-30$ and $6.25 \%(2 / 32)$ belonged to 31 - 40 range. Among the antiplatelet users 25\% (3/12) were in the 19 - 25 range, $41.6 \%(5 / 12)$ were in the range of $26-30$ and $33.33 \%(4 / 12)$ in the range of $31-40$.

\section{9) Hemoglobin levels}

$59.37 \%$ (19/32) of the cases had $\mathrm{Hb}>10 \mathrm{gm} \% .31 .25 \%$ (10/32) cases had $\mathrm{Hb}$ between 8 - 10 gm\%, 6.25 (2/32) between 6 - 8 gm\%. One case (3.12\%) had severe anaemia with $\mathrm{Hb}<6 \mathrm{gm} \%$ in the anticoagulant users.

$58.33 \%$ had $\mathrm{Hb}>10 \mathrm{gm} \%, 25 \%$ (3/12) cases had $\mathrm{Hb}$ between $8-10 \mathrm{gm} \%$, $8.3 \%(1 / 12)$ between $6-8 \mathrm{gm} \%$.

One case $(8.3 \%)$ had severe anaemia with $\mathrm{Hb}<6 \mathrm{gm} \%$ in the antiplatelet users 


\section{[27] (Figure 4, Table 4).}

\section{0) FSH level}

Serum FSH levels were estimated in $31.8 \%$ cases $(14 / 44) .8$ of the cases were anticoagulant users and 6 were using antiplatelet drugs. $12.5 \%(4 / 32)$ and 33.33 $(4 / 12)$ had levels $<15,3.12 \%(1 / 32)$ and $16.6 \%(2 / 12)$ of them in between $15-25$, 3 cases of the anticoagulant users who had levels of $>25$ were noted to have amenorrhea in the subsequent months of follow up (Figure 5, Table 5).
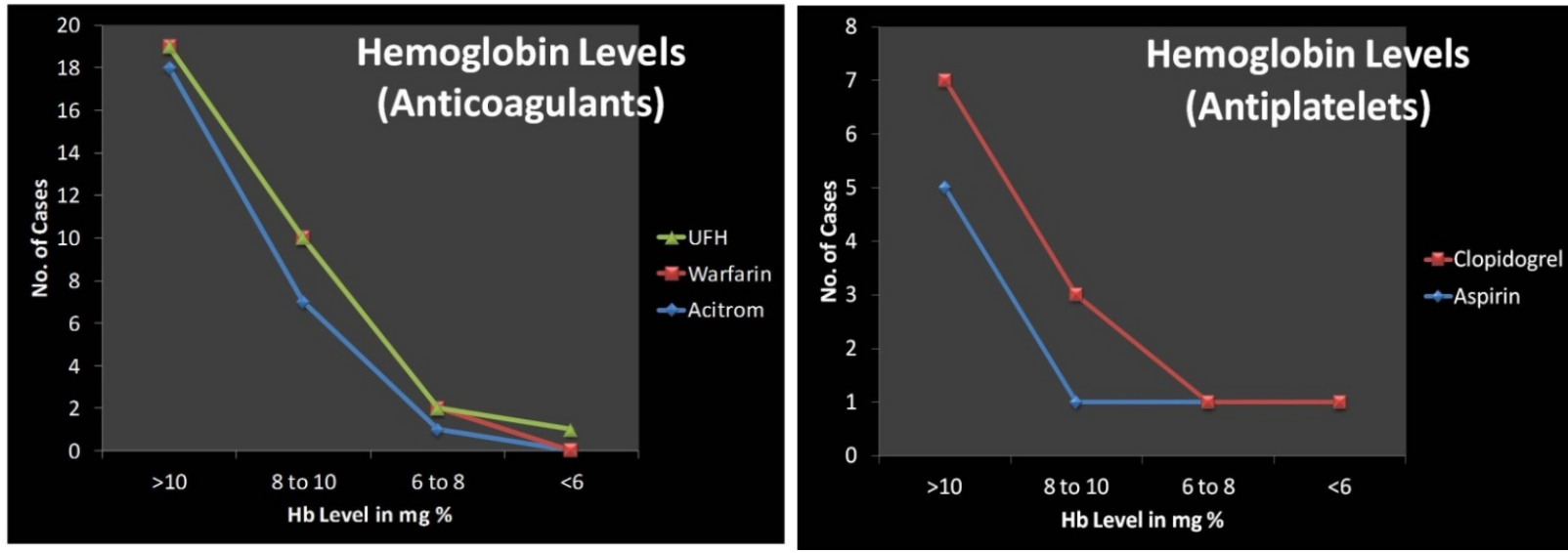

Figure 4. Anticoagulants\& Antiplatelets: haemoglobin levels.
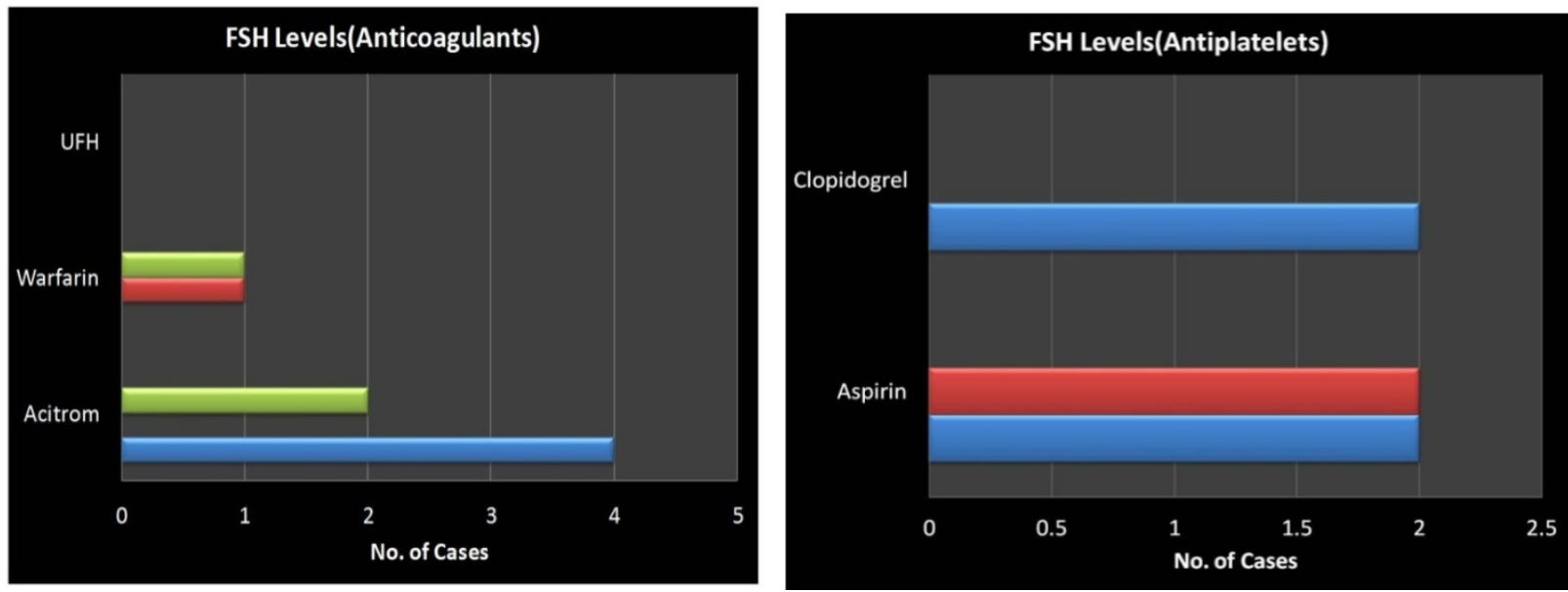

FSH levels $<15$

$15-25$

, $>25$

Figure 5. Anticoagulants \& Antiplatelets: FSH levels.

Table 4. Range of haemoglobin in anticoagulant and antiplatelet users.

\begin{tabular}{|c|c|c|c|c|c|c|c|c|c|}
\hline \multirow{2}{*}{ Range of $\mathrm{Hb}(\mathrm{gm} \%)$} & \multicolumn{3}{|c|}{ No. of cases } & \multirow{2}{*}{ Total } & \multirow{2}{*}{$\%(\mathrm{n}=32)$} & \multicolumn{2}{|c|}{ No. of cases } & \multirow{2}{*}{ Total } & \multirow{2}{*}{$\%(\mathrm{n}=12)$} \\
\hline & ACITROM & WARFARIN & UFH & & & ASPIRIN & CLOPIDOGREL & & \\
\hline$>10$ & 18 & 1 & - & 19 & 59.37 & 5 & 2 & 7 & 58.33 \\
\hline $8-10$ & 7 & 3 & - & 10 & 31.25 & 1 & 2 & 3 & 25 \\
\hline $6-8$ & 1 & 1 & - & 2 & 6.25 & 1 & - & 1 & 8.3 \\
\hline$<6$ & - & - & 1 & 1 & 3.12 & 1 & - & 1 & 8.3 \\
\hline Total & 26 & 5 & 1 & 32 & & 8 & 4 & 12 & \\
\hline
\end{tabular}


Table 5. FSH levels in 14 cases.

\begin{tabular}{|c|c|c|c|c|c|c|c|c|c|}
\hline \multirow{2}{*}{ FSH levels } & \multicolumn{3}{|c|}{ No. of cases } & \multirow{2}{*}{ Total } & \multirow{2}{*}{$\%(\mathrm{n}=32)$} & \multicolumn{2}{|c|}{ No. of cases } & \multirow{2}{*}{ Total } & \multirow{2}{*}{$\%(\mathrm{n}=12)$} \\
\hline & ACITROM & WARFARIN & UFH & & & ASPIRIN & CLOPIDOGREL & & \\
\hline$<15$ & 4 & - & - & 4 & 12.5 & 2 & 2 & 4 & 33.33 \\
\hline $15-25$ & - & 1 & - & 1 & 3.12 & 2 & - & 2 & 16.6 \\
\hline$>25$ & 2 & 1 & - & 3 & 9.37 & - & - & - & \\
\hline Total & 6 & 2 & - & 8 & 25 & 4 & 2 & 6 & 50 \\
\hline
\end{tabular}

Table 6. PBAC Score.

\begin{tabular}{|c|c|c|c|c|c|c|c|c|c|}
\hline \multirow{2}{*}{ PBAC score } & \multicolumn{3}{|c|}{ No. of cases } & \multirow{2}{*}{ Total } & \multirow{2}{*}{$\%(\mathrm{n}=32)$} & \multicolumn{2}{|c|}{ No. of cases } & \multirow{2}{*}{ Total } & \multirow{2}{*}{$\%(\mathrm{n}=12)$} \\
\hline & Acitrom & Warfarin & UFH & & & Aspirin & Clopidogrel & & \\
\hline$<100$ & 1 & - & - & 1 & 3.12 & 2 & - & 2 & 16.6 \\
\hline $100-200$ & 23 & 5 & 1 & 29 & 90.6 & 5 & 4 & 9 & 75 \\
\hline$>200$ & 2 & - & - & 2 & 6.25 & 1 & - & 1 & 8.3 \\
\hline
\end{tabular}

\section{1) Organic lesion}

In this study, evaluation to detect any co-existing organic lesion in pelvis was done. Among the anticoagulant users $25 \%(8 / 32)$ were detected to have fibroid, 9.3\% (3/32) had ovarian cyst. 3.12\% (1/32) had simple hyperplasia without atypia. In $62.5 \%$ (20/32) there was no pelvic pathology detected.

\section{2) PBAC Score}

PBAC score was calculated for all the cases per menstrual cycle. In the anticoagulant users $90.6 \%(29 / 32)$ the score was between 100 - 200. In $6.25 \%(2 / 32)$ it was $>200$. In one case who had no menstrual complaint the score was $<100$. In antiplatelet users $75 \%(9 / 12)$ the score was between $100-200$, one case (8.3\%) it was $>200$. In $16.6 \%$ the score was $<100$, out of which one case did not have any menstrual complaint and the other case presented with post menopausal bleeding per vaginum (Table 6).

\section{3) International Normalised Ratio (INR)}

$3 / 32$ of AC users and 7/12 of AP users had INR $<1,13 / 32$ and $3 / 12$ cases had INR in the range of $1-2,10 / 32$ and $2 / 12$ cases had INR in the range of $2-3$. Out of 4 cases on anticoagulants who had INR in the range of $3-4$, two of them had no organic lesion and two of them had uterine fibroids.

Two cases on anticoagulants had INR $>10$ and PT $>120$ (Figure 6, Table 7).

Secondary PPH: One was a 29 yrs old, P2 L2 who developed DVT of left lower limb on the $3^{\text {rd }}$ post operative day after LSCS. She was started on warfarin after adjusting the INR dose. 15 days later she presented with heavy bleeding per vaginum, INR was $>10$ and PT $>120$ secs. She was admitted, anticoagulants stopped, 4 units of FFP and inj Vit $\mathrm{K}$ was given. Before discharge 2 more units of FFP was given and restarted on warfarin.

Postmenopausal bleeding: The other case was a $51 \mathrm{yr}$ old postmenopausal lady with heavy bleeding and passage of clots since 3 days. On investigating her INR $>10$ and PT > 120 secs. Acitrom was stopped for 3 days, mefenamic acid 

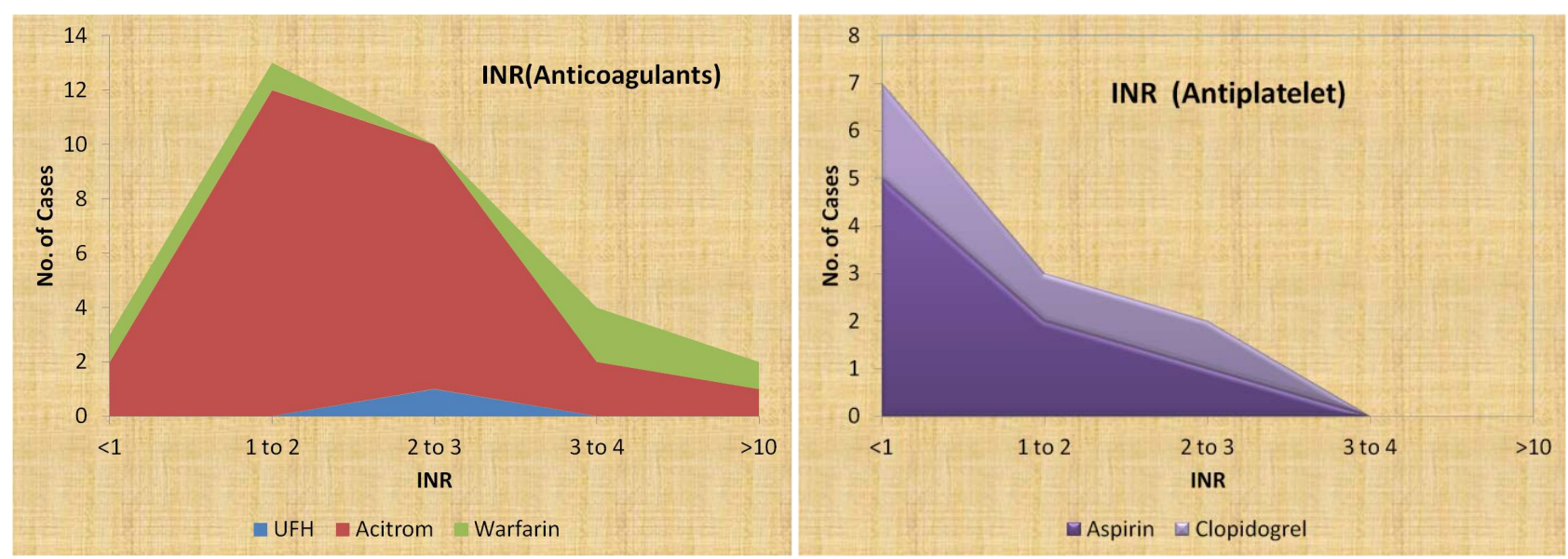

Figure 6. Anticoagulants \& Antiplatelets: INR.

Table 7. International Normalized Ratio.

\begin{tabular}{|c|c|c|c|c|c|c|c|c|c|c|}
\hline \multirow{2}{*}{ Sl no } & \multirow{2}{*}{ INR } & \multicolumn{3}{|c|}{ No. of cases } & \multirow{2}{*}{ Total } & \multirow{2}{*}{$\%(\mathrm{n}=32)$} & \multicolumn{2}{|c|}{ No. of cases } & \multirow{2}{*}{ Total } & \multirow{2}{*}{$\%(\mathrm{n}=12)$} \\
\hline & & Acitrom & Warfarin & UFH & & & Aspirin & Clopidogrel & & \\
\hline 1 & $<1$ & 2 & 1 & - & 3 & 9.37 & 5 & 2 & 7 & 58.33 \\
\hline 2 & $1-2$ & 12 & 1 & - & 13 & 40.62 & 2 & 1 & 3 & 25 \\
\hline 3 & $2-3$ & 9 & - & 1 & 10 & 31.25 & 1 & 1 & 2 & 16.6 \\
\hline 4 & $3-4$ & 2 & 2 & - & 4 & 12.5 & - & - & - & - \\
\hline 5 & $>10$ & 1 & 1 & - & 2 & 6.25 & - & - & - & - \\
\hline \multicolumn{2}{|c|}{ Total } & 26 & 5 & 1 & 32 & & 8 & 4 & 12 & \\
\hline
\end{tabular}

Table 8. Medical and surgical treatment of the gynaec problems in anticoagulant and antiplatelet users.

\begin{tabular}{|c|c|c|c|c|c|c|c|c|c|c|}
\hline \multirow{2}{*}{ Sl no } & \multirow{2}{*}{ Treatment } & \multicolumn{3}{|c|}{ No. of cases } & \multirow{2}{*}{ Total } & \multirow{2}{*}{$\%(\mathrm{n}=32)$} & \multicolumn{2}{|c|}{ No. of cases } & \multirow{2}{*}{ Total } & \multirow{2}{*}{$\%(\mathrm{n}=12)$} \\
\hline & & Acitrom & Warfarin & UFH & & & Aspirin & Clopidogrel & & \\
\hline 1. & Mefenamic acid & 16 & 5 & 1 & 22 & 68.75 & 3 & 3 & 6 & 50 \\
\hline 2. & Norethisterone & 5 & - & - & 5 & 15.6 & - & - & - & - \\
\hline 3. & Hysterectomy done & 3 & - & - & 3 & 9.37 & 2 & 1 & 3 & 25 \\
\hline 4. & Advised hysterectomy & 1 & - & - & 1 & 3.12 & 1 & - & 1 & 8.3 \\
\hline 5. & $\begin{array}{l}\text { Advised hysteroscopy \& } \\
\text { endometrial curettage }\end{array}$ & - & - & - & - & - & 1 & - & 1 & 8.3 \\
\hline 6. & No menstrual complaint & 1 & - & - & 1 & 3.12 & 1 & - & 1 & 8.3 \\
\hline
\end{tabular}

was given for 3 days. Repeat INR after 3 days was 3.62. Uterine bleeding stopped after 3 days.

\section{4) Management: Shown in Table 8.}

\section{Discussion}

The most common indication for anticoagulants was cardiac valve replacement, accounting for $50 \%$ of the total 32 cases. These patients have to be on anticoagulants for life time. There is a constant risk of uterine bleeding throughout their 
lifetime.

PBAC scores were calculated per menstrual cycle. In this study $90.6 \%$ and $75 \%$ of anticoagulant and antiplatelet users respectively had a PBAC score between 100 - 200. The mean and median PBAC score in this study was 130 and 120 respectively. In the study conducted by Huq et al. [6] the mean and median PBAC scores while on therapy were 200 and 210.

\section{Heavy menstrual bleeding:}

In this study $62.5 \%$ and $66.66 \%$ cases of anticoagulant and antiplatelet users respectively presented with menorrhagia,(HMB). Even postmenopausal bleeding was seen in patients on anticoagulants and antiplatelet agents. Women of reproductive age experience heavy and prolonged menstrual bleeding whilst on OA therapy. Mean duration of menses increased from 5.6 to 6.1 days $(\mathrm{P}<0.01)$, and reported menorrhagia from $44.2 \%$ to $70.8 \%(\mathrm{P}<0.001)$ [28]. Eighteen percent were treated for menorrhagia before and $29.9 \%$ during OA treatment $(\mathrm{P}<$ 0.01 ) [28]. Of 81 female adolescents on warfarin, 24, (30\%) were referred to gynaecology department for heavy periods [29].

Anticoagulants increase the risk of heavy menstrual bleeding (HMB). In menstruating women following VTE, rivaroxaban is associated with a two-fold higher risk of HMB compared with VKA. HMB predisposes to recurrent VTE episode, most likely due to the short interruptions of anticoagulation [30]. In a comparative study of rivaroxaban versus VKA, De crème et al [31] reported increased rates of prolonged menstrual bleeding ( $\mathrm{P}$-value 0.017 ), needing medical or surgical intervention (P-0.032) and anticoagulant therapy modification (P-0.031) in the rivaroxaban group. A recent meta-analyses suggested that use of rivaroxaban, apixaban and ximelagatran for acute or extended VTE treatment was associated with an increased rate of bleeding in women [32]. Therefore, therapeutic excesses can condition bleeding risk, and therapeutic limitation can increase thrombotic risk, especially when shortacting drugs such as the new oral anticoagulants are used. Hence, it is imperative to establish an appropriate method for monitoring new oral anticoagulants and to set the levels of safety and effectiveness by monitoring their anticoagulant effects [13].

\section{Anticoagulants, infertility and ART procedures:}

One woman on anticoagulants who was planning conception had two cycles of ovulation induction and IUI. When counseling had to be done regarding ART procedures, the cardiologist's opinion was sought. They were not in favour of ART procedures and gonadotrophin stimulation. In vitro fertilization may be considered where the risk of the procedure itself, including hormonal stimulation and pregnancy, is low. Thrombo-embolism may complicate in vitro fertilization when high oestradiol levels may precipitate a prothrombotic state [33].

Contraception in OA users: In this study, $56.25 \%$ of anticoagulant and $91.6 \%$ of antiplatelet users had undergone tubectomy as a method of permanent sterilization. Two were planning conception and four cases were in puerperium, did not need any form of contraception. In this study there was no case who was using OCP or IUCD. Contraceptive choices include barrier methods, steriliza- 
tion and progestin-only contraception orally, injection, implant and intrauterine system. In the study conducted by Huq et al. [6] 54.7\% changed their method of contraception after starting warfarin due to the thrombotic risk of estrogen preparations.

As per the WHO Medical Eligibility Criteria (MEC) 2015 [34], in women with $\mathrm{DVT} / \mathrm{PE}$ and established on anticoagulant therapy, combined pills are in category 4 , where as progesterone only pill, depot medroxy progesterone acetate, LNG intra uterine system are in category 2 and copper IUD in category 1 . It is a well established fact that estrogens increase the risk for VTE twofold to fourfold in a dose dependent way [35] The risk is also increased with progestins (synthetic progestogens such as norgestimate, desogestrel, and gestodene) of the third generation compared with those of the first or second generation (eg. ethisterone, norgestrel, and levonorgestrel) [35]. Oral anticoagulant therapy does not modify the bleeding pattern associated with the levonorgestrel-releasing intrauterine system in women with thrombophilia and/or a history of thrombosis [36].

Ida Martinelli [37] mentioning that product labels of combined oral contraceptives around the world state that active or prior VTE is a contraindication for their use, in their publication, states as a key point that estrogen containing or progestin only hormonal therapy is not associated with increased recurrent VTE risk in women on anticoagulant therapy.

Women suffer more bleeding complications than men when receiving new oral anticoagulants for VTE [38].

Fibromyoma and DVT:

In the study conducted by Huq et al [9] the indication was DVT in $44 \%$. In this study DVT was the indication in $15.62 \%$.The cases where fibroid was the cause of DVT [39], after the surgical treatment for fibroid, anticoagulants can be stopped after ensuring the recanalisation of the blood vessels. This prevents the patient from the prolonged or life long exposure of anticoagulants and their associated risks of major and minor bleeding episodes.

\section{Intra peritoneal bleeding:}

Two cases of intraperitoneal bleeding were successfully managed with conservative measures in our series. So an unnecessary laparotomy could be avoided by keeping the patient under observation. Gupta A. et al [40] reported conservative management of corpus leuteum haemorrhage in patients on anticoagulants. In a study by Wesley et al [41], massive intraperitoneal hemorrhage of ovarian follicular origin during anticoagulant therapy was managed conservatively.

\section{INR and bleeding complications:}

As per accepted norms the dose of the anticoagulants were adjusted in the therapeutic range so that the INR is maintained between 2 - 3. In this study $40.62 \%$ had INR in the range of $1-2$ and $31.25 \%$ had INR in the range of $2-3$. Two cases were seen with INR $>10$. Excessive uterine bleeding is a revealed form of bleeding which should alert the treating physician to monitor INR. In such cases remedial measures can be instituted early before any other fatal 
bleeding occurs. The inception cohort, observational ISCOAT study [42] showed that the lowest rate of bleeding $(4.8 \% \mathrm{pt} / \mathrm{yr})$ was in the $2.0-2.9$ INR category, where as the bleeding incidence increased exponentially for INR-values $>4.5$. TRILOGY ACS [43] report declared in 2012 said that the newer anticoagulants like rivaroxaban and vorapaxar caused increased bleeding when given on top of aspirin and clopidogrel, but aspirin is probably the worst culprit here.

In this study $68.73 \%$ of anticoagulant users and $50 \%$ of antiplatelet users showed improvement with NSAID-mefenamic acid. Norethisterone was the drug that was most effective to arrest menstrual bleeding in the cases that were seen in the immediate post operative period of cardiac surgery. Tranexamic acid is not recommended in these cases because of the theoretical possibility of increased risk of thrombosis. The efficacy and safety of the use of tranexamic acid in patients at higher risk for thromboembolism (such as those requiring anticoagulation) have not been established, but in general, these patients should not receive tranexamic acid [12].

\section{Hysterectomy:}

In our study, DVT was the indication for anticoagulant use in 5/32. Fibromyoma was the cause of DVT in two of the cases [39]. Anticoagulants could be stopped after hysterectomy, after recanalisation of the vessels. Estimating FSH levels has facilitated a conservative approach to manage HMB in women with small fibromyomata on OA therapy. We could reassure them that menopause is round the corner.

\section{Conclusions}

Oral anticoagulant therapy is increasingly used for the prevention and treatment of thromboembolic complications of cardiovascular disease. Bleeding is the most important complication of anticoagulant therapy and ranges from fatal, major to minor bleeding episodes. The use of INR increases the reliability of anticoagulant control. Monitoring with INR helps in avoiding unnecessarily high doses, associated with higher bleeding rates and optimum therapeutic ranges can be more easily achieved. Usually, intensity of anticoagulation achieved is related to bleeding. When bleeding events occur at very low INR it implies that many bleeds during oral anticoagulation are not related to the intensity of anticoagulation but to a local bleeding source that may be unmasked by anticoagulant therapy.

Women of reproductive age experience increased menstrual loss and change in menstrual pattern while on OA therapy. It is therefore recommended that all women of reproductive age on OA therapy should be provided with proper counselling about the possible changes in their menstrual pattern and increased menstrual bleeding. They should be monitored for HMB and other menstrual problems to ensure that appropriate treatment is instituted without delay and their quality of life improved. An unplanned pregnancy would lead to an increased risk of venous thromboembolism, and any further thromboembolic event presents a management dilemma in these patients who are already fully anticoagulated. They would also be at increased risk of intraoperative bleeding 
complications if they underwent a termination of pregnancy. These challenges highlight the importance of proper counselling about available contraceptive choices and the dangers that an unplanned pregnancy would present to these women.

\section{Acknowledgements}

We thank the team of cardiologists and cardiovascular surgeons at CARE hospitals, Hyderabad, for their cooperation to conduct this study.

\section{Compliance with Ethical Requirements and Conflict of Interest}

The authors declare that they have no conflict of interest.

\section{References}

[1] S. Orsola-Malpighi University Hospital (2011) The Risk of Bleeding with Anticoagulant Treatments-Review G. Palareti Division of Angiology and Blood Coagulation “M. Golinelli”. S. Orsola-Malpighi University Hospital, Bologna.

[2] Linkins, L.A., Choi, P.T. and Douketis, J.D. (2003) Clinical Impact of Bleeding in Patients Taking Oral Anticoagulant Therapy for Venous Thromboembolism: A Meta Analysis. Annals of Internal Medicine, 139, 893-900. https://doi.org/10.7326/0003-4819-139-11-200312020-00007

[3] Dewilde, W.J., Oirbans, T., Verheugt, F.W.A., Kelder, J.C., De Smet, B.J.G.L., Herrman, J.P., et al. (2013) Use of Clopidogrel with or without Aspirin in Patients Taking Oral Anticoagulant Therapy and Undergoing Percutaneous Coronary Intervention: An Open-Label, Randomised, Controlled Trial. The Lancet, 381, 11071115 .

[4] Dewilde, W. and Berg, J.T. (2009) Design and Rationale of the WOEST Trial: What Is the Optimal Antiplatelet and Anticoagulant Therapy in Patients with Oral Anticoagulation and Coronary StenTing (WOEST). American Heart Journal, 158, 713718.

[5] Hansen, M.L., Sørensen, R., Clausen, M.T., Fog-Petersen, M.L., Raunsø, J., Gadsbøll, N., et al. (2010) Risk of Bleeding with Single, Dual, or Triple Therapy with Warfarin, Aspirin, and Clopidogrel in Patients with Atrial Fibrillation. Archives of Internal Medicine, 170, 1433-1441. https://doi.org/10.1001/archinternmed.2010.271

[6] Huq, F.Y., Tvarkova, K., Arafa, A. and Kadir, R.A. (2011) Menstrual Problems and Contraception in Women of Reproductive Age Receiving Oral Anticoagulation. Contraception, 84, 128-132.

[7] Dilli, D., Oğuz, S. and Dilmen, U. (2011) A Case of Congenital Warfarin Syndrome Due to Maternal Drug Administration during the Pregnancy. Genetic Counseling, 22, 221-226.

[8] Yamakami, L.Y., de Araujo, D.B., Silva, C.A., et al. (2011) Severe Hemorrhagic Corpus Luteum Complicating Anticoagulation in Antiphospholipid Syndrome. Lupus, 20, 523-526. https://doi.org/10.1177/0961203310383300

[9] (2008) Coumarin Derivatives. In: Briggs, G.G., Freeman, R.K. and Yaffe, S.J., Eds., Drugs in Pregnancy and Lactation: A Reference Guide to Fetal and Neonatal Risk, 8th Edition, Wolters Kluwer-Lippincott Williams and Wilkins, Baltimore, 431-437.

[10] Barbosa, I., Olsson, S.E., Odlind, V., et al. (1995) Ovarian Function after Seven Years' Use of a Levonorgestrel IUD. Advances in Contraception, 11, 85-95. 
https://doi.org/10.1007/BF01987274

[11] Endrikat, J., Gerlinger, C., Richard, S., et al. (2011) Ovulation Inhibition Doses of Progestins: A Systematic Review of the Available Literature and of Marketed Preparations Worldwide. Contraception, 84, 549-557.

[12] Schwarz, E.B. and Longo, L. (2012) Special Considerations for Women of Reproductive Age on Anticoagulation. University of Pittsburgh and, PharmD, BCPS, VA PBM Services.

[13] Altman, R. (2014) New Oral Anticoagulants: Are Coagulation Units Still Required? Thrombosis Journal, 12, 3. http://www.thrombosisjournal.com/content/12/1/3 https://doi.org/10.1186/1477-9560-12-3

[14] Ruiz-Nodar, J.M., Marín, F., Roldán, V., Valencia, J., Manzano-Fernández, S., Caballero, L., et al. (2012) Should We Recommend Oral Anticoagulation Therapy in Patients with Atrial Fibrillation Undergoing Coronary Artery Stenting with a High HAS-BLED Bleeding Risk Score? Circulation: Cardiovascular Interventions, 5, 459466. https://doi.org/10.1161/CIRCINTERVENTIONS.112.968792

[15] Gage, B.F., Yan, Y., Milligan, P.E., Waterman, A.D., Culverhouse, R., Rich, M.W., et al. (2006) Clinical Classification Schemes for Predicting Hemorrhage: Results from the National Registry of Atrial Fibrillation (NRAF). American Heart Journal, 151, 713-719.

[16] Pisters, R., Lane, D.A., Nieuwlaat, R., de Vos, C.B., Crijns, H.J. and Lip, G.Y. (2010) A Novel User-Friendly Score (HAS-BLED) to Assess 1-Year Risk of Major Bleeding in Patients with Atrial Fibrillation: The Euro Heart Survey. Chest, 138, 1093-1100. https://doi.org/10.1378/chest.10-0134

[17] Fang, M.C., Go, A.S., Chang, Y., Borowsky, L.H., Pomernacki, N.K., Udaltsova, N., et al. (2011) A New Risk Scheme to Predict Warfarin-Associated Hemorrhage: The ATRIA (Anticoagulation and Risk Factors in Atrial Fibrillation) Study. Journal of the American College of Cardiology, 58, 395-401.

[18] Apostolakis, S., Lane, D.A., Guo, Y., Buller, H. and Lip, G.Y. (2012) Performance of the HEMORR (2) HAGES, ATRIA, and HAS-BLED Bleeding Risk-Prediction Scores in Patients with Atrial Fibrillation Undergoing Anticoagulation: The AMADEUS (Evaluating the Use of SR34006 Compared to Warfarin or Acenocoumarol in Patients with Atrial Fibrillation) Study. Journal of the American College of Cardiolo$g y, 60,861-867$.

[19] Donzé, J., Rodondi, N., Waeber, G., Monney, P., Cornuz, J. and Aujesky, D. (2012) Scores to Predict Major Bleeding Risk during Oral Anticoagulation Therapy: A Prospective Validation Study. American Journal of Medicine, 125, 1095-1102.

[20] Hallberg, L., Hogdahl, A.M., Nilsson, L. and Rybo, G. (1996) Menstrual Blood Loss-A Population Study. Variation at Different Ages and Attempts to Define Normality. Acta Obstetricia et Gynecologica Scandinavica, 45, 320-351. https://doi.org/10.3109/00016346609158455

[21] Fraser, I.S., McCarron, G. and Markham, R. (1984) A Preliminary Study of Factors Influencing Perception of Menstrual Blood Loss Volume. American Journal of $O b$ stetrics \& Gynecology, 149, 788-793.

[22] Reid, P.C., Coker, A. and Coltart, R. (2000) Assessment of Menstrual Blood Loss Using a Pictorial Chart: A Validation Study. BJOG, 107, 320-322. https://doi.org/10.1111/j.1471-0528.2000.tb13225.x

[23] Mansfield, P.K., Voda, A. and Allison, G. (2004) Validating a Pencil-and-Paper Measure of Perimenopausal Menstrual Blood Loss. Women's Health Issues, 14, 242-247.

[24] Warner, P.E., Critchley, H.O.D., Lumsden, M.A., et al. (2004) Menorrhagia I: 
Measured Blood Loss, Clinical Features, and Outcome in Women with Heavy Periods: A Survey with Follow-Up Data. American Journal of Obstetrics \& Gynecology, 190, 1216.

[25] Higham, J.M., O’Brien, P.M. and Shaw, R.W. (1990) Assessment of Menstrual Blood Loss Using a Pictorial Chart. British Journal of Obstetrics and Gynaecology, 97, 734. https://doi.org/10.1111/j.1471-0528.1990.tb16249.x

[26] Janssen, C.A., Scholten, P.C. and Heintz, A.P. (1995) A Simple Visual Assessment Technique to Discriminate between Menorrhagia and Normal Menstrual Blood Loss. Obstetrics \& Gynecology, 85, 977.

[27] World Health Organization (2011) Haemoglobin Concentrations for the Diagnosis of Anaemia. World Health Organization, Geneva. http://www.who.int

[28] Sjlander, A., Friberg, B., Svensson, P., Sticendal, L. and Lethagen, S. (2007) Menorrhagia and Minor Bleeding Symptoms in Women on Oral Anticoagulation. Journal of Thrombosis and Thrombolysis, 24, 39-41. https://doi.org/10.1007/s11239-006-0003-7

[29] Peake, L.J., Grover, S.R., Monacle, P.T. and Kennedy, A.D. (2011) Effect of Warfarin on Menstruation and Menstrual Management of the Adolescent on Warfarin. Journal of Paediatrics and Child Health, 47, 893-897. https://doi.org/10.1111/j.1440-1754.2011.02101.x

[30] Bryk, A.H., Pirog, M., Piens, K. and Undas, A. (2016) Heavy Menstrual Bleeding in Women Treated with Rivaroxaban and Vitamin K Antagonists and the Risk of Recurrent Venous Thromboembolism. Vascular Pharmacology, 87, 242-247.

[31] De Crem, N., Peerlinck, K., Vanassche, T., et al. (2015) Abnormal Uterine Bleeding in VTE Patients Treated with Rivaroxaban Compared to Vitamin K Antagonists. Thrombosis Research, 136, 749-753.

[32] Alotaibi, G.S., Almodaimegh, H., Sean, M.M. and Cynthia, W. (2013) Do Women Bleed More than Men When Prescribed Novel Oral Anticoagulants for Venous Thromboembolism? A Sex Based Meta-Analysis. Thrombosis Research, 132, 185 189.

[33] Regitz-Zagrosek, V., et al. (2011) ESC Guidelines on the Management of Cardiovascular Diseases during Pregnancy. European Heart Journal, 32, 3147-3197.

[34] WHO Medical Eligibility Criteria for Contraception-MEC, 2015. Geneva.

[35] (1995) Effect of Different Progestogens in Low Oestrogen Oral Contraceptives on Venous Thromboembolic Disease. World Health Organisation Collaborative Study of Cardiovascular Disease and Steroid Hormone Contraception. The Lancet, 346, 1582-1588.

[36] Braga, G.C., Brito, M.B., Ferriani, R.A., Oliveira, L.C., Garcia, A.A., Pintao, M.C. and Vieira, C.S. (2014) Oral Anticoagulant Therapy Does Not Modify the Bleeding Pattern Associated with the Levonorgestrel-Releasing Intrauterine System in Women with Thrombophilia and/or a History of Thrombosis. Contraception, 89, 4853.

[37] Martinelli, et al., (2015) Recurrent Venous Thromboembolism and Abnormal Uterine Bleeding with Anticoagulant and Hormone Therapy Use. American Society of Hematology.

[38] Lapner, S., Cohen, N. and Kearon, C. (2014) Influence of Sex on Risk of Bleeding in Anticoagulated Patients: A Systematic Review and Analysis. Journal of Thrombosis and Haemostasis, 12, 595-605. https://doi.org/10.1111/jth.12529

[39] Devabhaktuni, P., Gupta, P.C., Bhupatiraju, S., Puranam, B. and Abdul, S.M. (2014) Uterine Fibromyoma and Intravascular Thrombosis-Eight Cases. Open Journal of 
Obstetrics and Gynecology, 4, 197-207. http://www.scirp.org/journal/ojog https://doi.org/10.4236/ojog.2014.44033

[40] Gupta, A., Gupta, S., Manaktala, U., Gupta, M.M. and Solanki, V. (2015) Conservative Management of Corpus Luteum Haemorrhage in Patients on Anticoagulation: A Report of Three Cases with Review of Literature. Archives of Gynecology and Obstetrics, 291, 427-431. https://doi.org/10.1007/s00404-014-3394-2

[41] Wesley, A.C., Neustader, M.I. and Levine, W. (1957) Massive Intraperitoneal Hemorrhage of Ovarian Follicular Origin during Anticoagulant Therapy. American Journal of Obstetrics \& Gynecology, 73, 683-685.

[42] Palareti, G., Leali, N., Coccheri, S., et al. (1996) Bleeding Complications of Oral Anticoagulation Treatment: An Inception-Cohort, Prospective Collaborative Study (ISCOAT). Italian Study on the Complications of Oral Anticoagulation Therapy. The Lancet, 348, 423-428.

[43] TRILOGY ACS, Acute Coronary Syndrome (ACS). http://www.theheart.org/article/1437675.do

\section{Scientific Research Publishing}

Submit or recommend next manuscript to SCIRP and we will provide best service for you:

Accepting pre-submission inquiries through Email, Facebook, LinkedIn, Twitter, etc. A wide selection of journals (inclusive of 9 subjects, more than 200 journals)

Providing 24-hour high-quality service

User-friendly online submission system

Fair and swift peer-review system

Efficient typesetting and proofreading procedure

Display of the result of downloads and visits, as well as the number of cited articles

Maximum dissemination of your research work

Submit your manuscript at: http://papersubmission.scirp.org/

Or contact ojog@scirp.org 